\title{
O futebol na construção da identidade nacional: uma análise sobre os jogos "pretos x brancos"
}

CDD. 20.ed. 796.05

796.33
Bruno Otávio de Lacerda ABRAHÃO* Antonio J orge Gonçalves SOARES*
*Instituto Metodista Izabela Hendrix.

** Universidade Federal do Rio de Janeiro.

\section{Resumo}

Este artigo objetiva compreender os significados de uma partida de futebol entre jogadores autodeclarados pretos e brancos que ocorreram em São Paulo, no dia 13 de Maio, data comemorativa do fim da escravidão: o jogo "Preto x Branco". Para tanto, concentramo-nos nas matérias jornalísticas publicadas pelos principais periódicos de São Paulo entre os dias 10 a 15 de Maio entre 1927 até 1939, período de realização dos jogos. Além dos jornais, foi visitado o museu da Federação Paulista de Futebol que disponibilizou as informações necessárias para entendermos a trajetória desses jogos. Concluímos que a idealização de uma partida dessa natureza no dia "13 de maio" teria como função, além de prevenir do esquecimento e manter viva a lembrança da escravidão, reforçar a imagem de um país que era tomado como um modelo a ser seguido no que diz respeito ao tema étnico-racial.

UNITERMOS: Futebol; Identidade nacional; Jogo "Preto x Branco".

\section{Introdução}

Se os esportes não são independentes em relação à sociedade na qual eles se desenvolveram e seus valores são atualizados em conformidade com a estrutura social em que estão inseridos, pergunta-se: que significados assumiram as partidas de futebol entre jogadores autodeclarados pretos e brancos que ocorreram em São Paulo, 39 anos após a formalização do fim da escravidão, na comemoração do dia "13 de Maio" entre os anos de 1927 e 1939? Este artigo vai buscar compreender os significados desse jogo chamado de "preto x branco".

Pensadas paralelamente às interpretações nacionalistas sobre a mestiçagem, no contexto pósabolição, na fase da implantação da República e do trabalho liberal no Brasil, tais partidas apresentam uma rica gama de significados sobre o debate racial na sociedade brasileira e as representações sobre as "raças" em uma sociedade que passava a ser constrangida pelos códigos de uma ordem liberal. Realizados com toda pompa que merecem os grandes cerimoniais nacionais, esses eventos singulares idealizados para celebrar a emancipação política dos ex-escravos refletiam as demandas daquele contexto histórico.

Uma partida festiva de futebol disputada entre uma equipe de jogadores pretos e outra equipe composta por jogadores brancos dramatizava os dilemas identitários acerca das raças naquela ordem pós-escravocrata, momento em que o Brasil republicano buscava a afirmação de sentidos e símbolos de coesão social que constituíam imagens sobre o ser brasileiro. Por isso, acreditamos que as representações oriundas dessas partidas amistosas realizadas nas primeiras décadas do século XX podem auxiliar a entender o debate sobre o "racismo à brasileira", bem como as tensões e consensos sobre a constituição da brasilidade. 


\section{Procedimentos metodológicos}

Tomamos como fontes as textualidades elaboradas sobre os jogos através das matérias publicadas pela imprensa convencional da cidade de São Paulo e pela "imprensa negra" - as "associaçôes de homens de cor" (PIREs, 2005). Foi realizada uma incursão até os microfilmes da Biblioteca Nacional, no Rio de Janeiro, para captar o significado do "Preto x Branco" através de discursos que nos permitissem apreender como se produziram, difundiram e repercutiram as interpretações dos fatos, muitas vezes em diversas versōes. Os conteúdos dessas matérias jornalísticas revelam significados, valores e representações circulantes na dinâmica social, constituindo formas subjetivas de pensar as "raças", categorias nativas entendidas aqui em termos antropológicos.

Andrews disse que essas partidas eram realizadas anualmente, a cada 13 de maio, de 1927 até 1930 . Desconfiei dessa informação e resolvi checar os jornais do ano de 1931, quando encontrei a ocorrência do "Preto x Branco" também naquele ano. Posteriormente, lendo um livro que resgata parte da história do futebol de São Paulo, descobri que os jogos ocorreram ainda em 1938 e 1939, havendo uma interrupção entre 1932 e 1937, a julgar pela sua ausência nos jornais. Pelo menos é isso que podemos inferir do fato de não ter encontrado mais comentários sobre os jogos, apesar da procura exaustiva.

Tentando apreender uma interpretação sobre os jogos de maneira mais generalizante e menos inclinada e comprometida com a questão negra, foram consultados os microfilmes dos jornais da imprensa convencional de São Paulo, mas que tinham circulação nacional. Os jornais foram aqueles disponibilizados em microfilme pela Biblioteca Nacional: Correio Paulistano, O Estado de S. Paulo e Folha da Manhã, entre os anos de 1927 e 1931, de 1938 e de 1939. Realizei leitura dos microfilmes dos dias 10 a 14 de maio de cada um desses anos, a fim de apreender a divulgação, a promoção e a repercussão do jogo.

Estamos partindo da análise interpretativa dos significados que fundam uma cultura (GEERTZ, 1973). Isto é, estaremos "explicando as explicaçōes". Nosso olhar sobre as matérias a que tivemos acesso é um olhar de segunda mão. As fontes jornalísticas são, em si, interpretaçōes elaboradas sobre os jogos ${ }^{1}$, que expressavam as demandas daquele contexto histórico e os predicados sobre as identidades dos sujeitos envolvidos naquelas partidas.

\section{Os significados do "Preto x Branco"}

A popularização do futebol em São Paulo sintetizava importantes tensões daquela sociedade recentemente republicana e liberal. Uma delas era os preconceitos que emergiram contra os negros naquele momento em que o futebol começava a se difundir no Brasil em todos os segmentos sociais. Todavia, não obstante os negros começavam a ter visibilidade no esporte e nas artes, eles continuavam tendo sua participação circunscrita a determinados espaços de atuação, sendo preteridos nas redes sociais dos principais clubes esportivos da capital paulistana.

Vivendo sob o "ethos" amador, a divisão social de futebol ainda perdurava naquela cidade. Os principais jogadores negros e brancos ainda estavam confinados em times separados, sem oportunidades de jogar uns com os outros, exceto em disputas informais. Num esforço de abalar essa divisão e fazer com que os primeiros fossem mais vistos, "em 1927 vários líderes negros tiveram a ideia de realizar um jogo anual entre negros e brancos, a ser disputado no dia da aboliçãa” (ANDREWs, 1998, p.333).

ANDREWs (1998) salienta ainda que após a Proclamação da República houve um desencorajamento das comemorações do dia 13 de maio. Apesar disso, a comemoração dessa data nunca desapareceu totalmente, tendo sido preservada como um feriado cívico pelas organizações sociais dos negros. Nesse sentido, todos os anos eram realizados eventos patrocinados pelos clubes sociais dos negros, que, em geral, compunham-se de atividades "civilizadas" como música, poesia, bailes, partidas e eventos esportivos, entre os quais partidas daquela natureza, que tiveram início no final da década de 20 e avançaram até os anos 1930. Posteriormente, em contato com os principais jornais daquele período, descobri que o "Preto x Branco" foi uma iniciativa da Liga de Amadores de Futebol, a LAF, criada em 1926, e não uma idealização das organizações negras. Essas últimas passaram a cooperar na organização do 
evento a partir de 1931, quando a LAF encerrou suas atividades. Veremos isso à frente.

A LAF surgiu em 1926, oriunda de uma dissidência do Paulistano, que, visando uma renovação de seus hábitos e costumes, resolveu se desligar da APEA, instituição que naquela ocasião deliberava sobre os rumos do futebol paulista. Ainda preso ao amadorismo e à elitização do esporte, o Paulistano propôs a criação da LAF com o objetivo de renovar os ares da política esportiva, pois, segundo a visão desse clube, imperava nos clubes filiados à APEA a indisciplina, a "politicagem" e o falso amadorismo. O "falso amadorismo", marco da "transição" do amadorismo para o profissionalismo, foi a justificativa para que o Paulistano propusesse, em 1926, a fundação da LAF.

Por não concordar com os caminhos da profissionalização para a qual o futebol caminhava e a APEA inclinava-se favoravelmente, a LAF, logo no seu primeiro ano de existência e em conformidade com o interesse da maioria de seus membros, resolveu idealizar e promover aquela partida original. De forma inédita e até certo ponto contraditória - já que a instituição dissidente do futebol paulista se mantinha elitista e presa aos valores do amadorismo -, a LAF passou a promover a tal partida de futebol sem fins lucrativos. Em tese, diferente da ordem escravocrata, esse jogo causava uma suspensão, ainda que temporária, na hierarquização velada vigente na vida cotidiana, e equiparava pretos e brancos a partir do mesmo código jurídico, na medida em que as regras proporcionavam a oportunidade de vitória para ambas as equipes.

A primeira edição do "Preto x Branco" foi realizada no dia 13 de Maio de 1927, tendo sido farta e antecipadamente anunciada pelos três principais jornais de São Paulo.

Football

O grande festival de hoje no campo do Palmeiras Combinado Preto VS. Combinado Branco da LAF - outras notas

Finalmente hoje a Liga de Amadores de Football fará realizar, no campo da A. A. das Palmeiras, na Chácara da Floresta, Ponte Grande, o esperado e interessante festival com que essa entidade iniciará a disputa de um trophéo que, em comemoração á grande data da abolição no Brasil, foi instituído por essa entidade para jogos que se realizarão annualmente na mesma data entre um selecionado preto e outro de brancos.

O trophéo que se disputa hoje pela primeira vez e que só ficará de posse definitiva dos vencedores em três anos consecutivos ou 4 alternados, foi offerecido pelo Sr. Dr. Dino Bueno, presidente do Estado 2 , que denomina "Princeza Izabel".

São estes os selecionados que hoje vão enfrentar-se para a primeira partida em disputa deste premio. Selecionado branco. Nestor - Clodoaldo - Bastho - Raphael - Vanni - Gelindo - Apparicio - Néco - Friedenreich - Romeu Guimarães.

Selecionado Preto: Dica (P. P.), Francisquinho - Ferreira (independência) - Cunhal (R. Claro), Mono (Antarctica) - Rogério (Santista) - Bisoca (Syrio) - Nabor (PP) - Camargo (Jundiahy) Gradin e Carrapicho (PP).

Arbitrará a partida o Sr. Joaquim de Almeida.

Antes desse encontro, como preliminar, serão realizadas 2 partidas entre os selecionados colegiaes da Liga, sendo conferidas aos vencedores dos quadros principaes medalhas de prata, todas oferecidas pela LAF.

O festival de hoje tem conquistado a simpathia de todos, como se prova pelo facto do próprio presidente do Estado offerecer uma taça e nada mais justo que isso, pois, além de dar a nova entidade esportiva uma significativa prova de elevação do espírito esportivo com que seus diretores encarnam as cousas esportivas, deixando de parte todo e qualquer preconceito entre os brasileiros - com a festa de hoje a Liga de A. de Footbal visa beneficiar a Associação dos Homens de Côr, pois que em um gesto altamente altruístico, resolveu que parte da renda do jogo reverta em benefício daquela associação.

Para maior brilho do festival o aviador Sr. Fritz Boesler durante a reunião realizará interessantes e perigosas evoluçóes em seu aeroplano atirando flôres sobre o campo do Palmeiras. É este, sem duvida, mais um grande attractivo para o festival de hoje. Consoante têm sido noticiado, a Liga de Amadores de Football convidou especialmente todas as altas autoridades civis e militares do Estado, bem assim como o Exmo. Sr. Dr. Washington Luís, Sr. Antonio Prado Fr., Prefeito do Districto Federal e presidente honorário da LAF, e o secretário do mesmo. Dr. Mario Cardim, conhecido e acatado esportista, fundador da Liga de Amadores de Football.

Tudo que foi dito serve para garantir um completo sucesso á grade festa de hoje que se iniciará a praxe da LAF, em commemorar condignamente, todos os annos, á grande data de 13 de maio.

As entradas para o festival estão à venda, há dias nas casas "São Nicolau" e "Stadium Paulista", 
sendo estes os seus preços:

Archibancada $4 \$ 000$

Geraes 2\$000 (Correio Paulistano, 13/05/1927, Sport, p.5).

Talvez tenha sido o fato de ser inclinada aos valores amadores do esporte que motivou a nova instituição a idealizar essa partida festiva e amistosa, com o objetivo de celebrar o fim da escravidão e a emancipação dos escravos. A opção da nova instituição por positivar a questão racial brasileira fortalecia a ética amadora de que a finalidade da competição deveria encerrar-se nela mesma, por prazer, e não por estar presa a nenhuma finalidade pecuniária. Prova disso, como veremos à frente, é que não havia nenhuma recompensa econômica para a vitória de uma ou outra equipe. A supremacia de um time sobre outro era traduzida em termos simbólicos pela conquista de uma taça que levava o nome da princesa redentora dos escravos.

O governo do estado de São Paulo era um dos principais incentivadores do evento, pois iria conceder a tal taça que simbolizaria, dentre outras coisas, a superioridade das raças no campo de futebol. Além de começar a anunciar osignificado daquela partida, a matéria a seguir revela que a equipe que vencesse os jogos por três anos consecutivos ou quatro alternados ficaria com a posse definitiva da taça "Princesa Izabel". No dia do jogo os jornais trouxeram maiores detalhes, como a escalação das equipes, o nome dos árbitros, os beneficiados pelo evento.

A matéria revela que os festejos do "13 de maio" não se reduziam ao jogo "Preto x Branco". Ele era a principal atração de um evento que era composto por outros atrativos, como um jogo realizado entre as equipes colegiais da LAF, contando inclusive com premiação para os vencedores, além da apresentação de aeroplanos que descarregavam rosas sobre o gramado.

Além disso, para compor o cenário de festividade, a matéria revela como esse festival se revestiu de toda pompa dos grandes festejos ou cerimoniais nacionais, sobretudo por terem sido convidadas a participar do evento as mais altas autoridades civis, militares e esportivas, dentre as quais merece destaque a possível presença do Presidente da República em exercício naquela ocasiāo, o Sr. Washington Luís. Tudo isso no principal estádio de São Paulo.

A realização desse jogo serviria para mostrar que o Brasil, mesmo com a memória da escravidão ainda recente na mentalidade daquela sociedade, soubera superar o preconceito contra aqueles anteriormente visto como inferiores. Chama a atenção, para simbolizar esse valor caro à brasilidade, o gesto de filantropia e amor ao próximo da LAF ao reverter parte da renda do jogo para as "associações dos homens de cor”. Isso representaria o nível elevado em que os brasileiros se posicionariam com relação às questôes raciais.

O Estado de S. Paulo trouxe outros detalhes sobre o jogo no dia 13.

Futebol

A commemoração da Lei Áurea

Combinado branco vs combinado preto

Effectua-se hoje no campo do Palmeiras, um grande jogo de futebol entre dois combinados dos melhores elementos da Liga de Amadores de Futebol. Tem um certo cunho de originalidade essa partida, pois as turmas são formadas de jogadores da cor branca, uma, e de cor preta, outra. Dentre as várias iniciativas que tem tomado a LAF na sua breve mas fecunda existência, poucas foram recebidas com tantos applausos como a desse Festival Esportivo. É que commemora a passagem da data da assignatura da "Lei Áurea", votada em 1888, com applauso unânime da opinião popular. A razão da sympatia que encontrou nessa capital a lembrança dos directores da liga, hoje effectivada, não está tanto no sentir dos brasileiros, fundamentalmente avessos a distincções de família e de cor, guiando-se mais pelo grau de mérito individual, como porque vale a oporttunidade para uma resposta indirecta. Aquelles poucos esportistas que nos centros náuticos, principalmente, tem pretendido estabelecer exclusivismos odiosos tentando votar regras que deixem a margem os que, desejando praticar o esporte de remo no nosso estado, não tenham a sorte de possuir pigmentação intocavelmente caucásia...

Os mentores da LAF ao promover o grande encontro de futebol entre o combinado branco e o combinado negro, não o fizeram, entretanto, com o intuito de mover picuinhas. Tanto mais que o esporte por ela patrocinado está bem fora do âmbito em que se acham os agora empenhados na campanha inglória de alijar dos centros náuticos os esportistas de cor. Mas nem por isso a competição de hoje deixa de ter excepcional relevo, pois em qualquer outra ordem de actividade não se justifica esse preconceito odioso, muito menos por ser ele tolerado no esporte, onde o elemento de cor tem dado sobejas provas de energia, tanto no atletismo como no futebol, para citar somente essas duas modalidades esportivas, onde existe mais elevado coefficiente de negros. 
De modo que hoje o encontro preto vs branco, além da opportunidade de confraternização vae constituir um soberbo torneio esportivo.

O troféu que se disputará hoje pela primeira vez e que só ficará de posse definitiva após três annos de victórias consecutivas ou quatro alternadas foi offerecido pelo Exmo. Senhor Dino Bueno actual presidente do estado, que a denominou Princesa Isabel (O Estado de S. Paulo, 13/05/1927, p.6).

Nesse texto o Estado de S. Paulo apresentou os detalhes sobre aquele jogo que opunha e igualava pretos e brancos, antes hierarquizados pela ordem escravocrata. Adjetivada de original, essa iniciativa reforçava um discurso proclamado de que o brasileiro seria um povo avesso ao preconceito racial. Em contrapartida, o jornal reverbera a denúncia de que os negros ainda eram preteridos nos clubes náuticos de São Paulo, onde persistiam resquícios de preconceito e discriminação velada praticados em São Paulo nas primeiras décadas do Século XX. Essa postura foi adjetivada como "inglória”, revelando como ser racista no Brasil é um valor repudiado. Agravava-se ainda o fato de esse comportamento se manifestar no âmbito do esporte, campo onde o mérito do negro começava a ser reconhecido e positivado.

Diante de uma torcida numerosa e empolgada, a "seleção negra" venceu a dos "brancos" por 3 a 2. No dia 14, o jogo repercutiu nos três principais jornais de São Paulo:

Football

Liga de Amadores de Football

A competição de hontem em homenagem a data de 13 de maio - victória do combinado negro outras notas

Teve um brilhante característico a festa sportiva organizada para hontem pela diretoria da Liga de Amadores de Football para commemorar este anno a passagem da data que relembra um dos fatos de mais repercussão e relevo na história política do país: a emancipação dos escravos. E foi digna de maiores elogios a magnífica iniciativa da commissão technica dessa nova corporação de sports, fazendo disputar um torneio em que somente se empenhassem os homens que expressassem em sua admirável grandeza a raça que foi emancipada em um gesto dos mais nobres pela nossa grande princesa. $\mathrm{O}$ jogo em que se empenharam os conjuntos preto e branco teve uma movimentação technica fora do commum, assumindo as vezes proporçôes das mais renhidas das pelejas de "association", até hoje realizadas pela nova instituição de São Paulo. O aspecto do campo, a confortável praça de sports da velha sociedade da Floresta, uma das que, incontestavelmente, maior número de espectadores comporta - era dos mais admiráveis. Uma multidão compacta e enthusiasta que emprestou ao torneio toda a attitude febril de sua mais intensa vibração, proporcionou nos vinte e dois elementos que no campo competiam pela primazia technica do domínio dos sports, um incentivo peculiar a essas exhibiçôes, animando-os em todas as investidas sem par que conseguiram levar a termo.

A Parte Technica

Eram precisamente 16 horas e quarenta minutos quando entram em campo as duas equipes, formadas pela commissão technica e queriam disputar a posse da taça instituída pelo senhor presidente do estado e que recebeu o nome de "Princesa Isabel". As duas representações saldam nos pavilhões officiaes a frente da arquibancada os destemidos tripulantes do avião "JAHU", que realiza a travessia do Atlântico. Essas saudações são recebidas com geral agrado pelos espectadores. Depois de tiradas as chapas photográphicas dá-se inicio ao jogo cabendo o tiro inicial ao senhor Gastão Rachou, presidente em exercício da Liga de Amadores que começa o torneio, passando a esphera ao grande Neco.

Após a realização do torneio foi entregue ao capitão da turma preta a taça de prata, objeto de encontro gentilmente offertada pelo senhor presidente do Estado.

Aos elementos da turma vencedora foram igualmente conferidas as medalhas de ouro, que a directoria da Liga de Amadores lhes havia destinado. (Correio Paulistano, 14/05/1927, p.6).

A partir das escalações de ambos os quadros podemos observar que o time dos pretos venceu um adversário em que seus principais jogadores - Neco e Friedenreich - foram os protagonistas da jogada que resultou no gol que proporcionou a vitória histórica do Brasil, oito anos antes, contra o Uruguai, no SulAmericano de 1919, como descrito por Mário Filho. um mulato, porém, Arthur Friedenreich se tornaria o maior ídolo do futebol brasileiro. Não porque muita gente pensa. Tivesse marcado o gol da vitória de 19[19]. O gol foi menos dele do que de Neco.

Neco é que trouxe a bola do meio de campo, que a carregou até a linha de corner, que deu o passe para Friedenreich. Friedenreich só fez encostar o pé na bola. A bola entrou, mansamente. Era a vitória (Rodrigues Filho, 1964, p.69). 
A participação desses jogadores reconhecidamente prestigiados naquela partida servia para engrandecê-la ainda mais e denotar com mais força o valor e a qualidade da equipe dos pretos, que conseguiu vencer uma equipe composta de adversários do nível da seleção brasileira, em tese os melhores em atividade no Brasil.

$\mathrm{O}$ jogo continuou sendo repercutido pelos principais jornais de São Paulo.

Futebol

A commemoração da Lei Áurea

Combinado branco vs combinado preto

A brilhante victória dos negros por 3 a 2

Teve êxito superior a expectativa o festival que, sob o patrocínio da Liga de Amadores de Futebol, se realizou hontem no campo do Palmeiras, para commemorar a data da abolição da escravatura no Brasil.

Esse festival, consoante o noticiado, constou de dois jogos, o primeiro, entre combinados collegiaes, o segundo, entre dois selecionados característicos, o sellecionado official da LAF, com ligeiras modificaçôes, e um combinado de elementos de cor [...]

A festa despertou notável interesse na massa popular esportiva da capital. O campo do Palmeiras estava literalmente cheio uma hora e meia antes de se iniciar o jogo principal. [...]

Findo o jogo, os elementos do quadro preto foram carregados em triunpho pela assistência. $\mathrm{O}$ juiz do segundo tempo foi bem. (O Estado de S. Paulo, sábado, 14/05/1927, p.6).

O Estado reverbera alguns pontos e adiciona o fato de que aquele evento original despertou a atenção da população da capital paulista que se interessava por esportes, e que, a fim de comemorar a vitória dos pretos, chegou ao ponto de carregá-los. A assistência, adjetivada de "colossal", que se direcionou ao campo do Palmeiras superou as expectativas, segundo a Folha da Manhã.

O festival de hontem da LAF.

$\mathrm{O}$ selecionado preto venceu o branco.

Se era esperado que o festival promovido hontem pela Liga de Amadores de Futebol conseguisse completo sucesso verificou-se no decorrer do mesmo que elle ultrapassa ainda a estas expectativas. Uma assistência colossal enchia completamente as vastas dependências do campo e notava-se em todos desusado interesse e enthusiasmo pela partida que ia travarse dahi há pouco entre dois selecionados da Liga, um de jogadores pretos e outro de elementos brancos, em disputa da taça Princesa Izabel [...] (FolHA DA ManHĀ, 14/05/1927, p.8).
O sucesso dessa partida disputada no ano anterior fez com que o evento fosse repetido e aguardado com muita expectativa pela imprensa e pelos torcedores em 1928. A partir do dia 9, portanto quatro dias antes do jogo, começou a sua divulgação.

LAF

Comunicado oficial SELECIONADO BRANCO VS SELECIONADO PRETO

O conselho técnico da Liga de Amadores de Football, em reunião realizada ontem, deliberou realizar amanhã, 5a feira, um rigoroso treino para os selecionados Branco e Preto, que deverão enfrentar-se no próximo dia 13 de maio. [...] Para a organização e fiscalização foram designados os seguintes membros do conselho técnico: José Ozzetti e Raul e Moura, para o campo do Antarctica F. C.; Manuel Furtado de Oliveira e Raul Zucho, para o campo da A. A. São Paulo. (Correio Paulistano, 09/05/1927, Sport, p.6).

$\mathrm{O}$ ano de 1928 teve um diferencial: haveria um treino preparativo para o jogo. No dia 10 de maio o jornal O Estado de S. Paulo destacou esse treino, e nos três dias seguintes anunciou o jogo. Mas foi no Correio Paulistano que o jogo ganhou maior destaque.

Em disputa da taça Princesa Izabel

Realiza-se hoje, no gramado da A. A. das Palmeiras "Ponte Grande", o encontro promovido pela LAF, entre os seus dois combinados, um formado por jogadores brancos e outro formado por jogadores de cor.

A entidade da rua João Briccola, desejando homenagear a grande data do 13 de maio, no ano passado instituiu os jogos entre os selecionados alludidos combinados, obtendo a mais franca aceitação e ruidoso sucesso, para a sua feliz idéia. O exmo. Sr. Dr. Bino Bueno (presidente do Estado) externou desde logo a sua sympathia para com o emprehendimento da Liga, offertando a magnífica taça "Princesa Izabel", qual foi ganha pelo selecionado dos homens de cor, perante numeroso público que agarrou ao campo da Floresta e de lá sahiu satisfeito pela magnífica técnica da disputa. [...]

A LAF convidou para a sua festa as altas autoridades federaes, estaduaes e municipaes, as quaes terão logar reservado no pavilhão de honra da A. A. das Palmeiras.

O presidente da LAF, Sr. Antonio Prado Jr., prefeito do Districto Federal, deverá chegar hoje a esta capital, especialmente para assistir essa competição. 
Hontem a sua diretoria recebeu um telegrama do exmo. sr. dr. Washington Luis, presidente da República, o qual agradecendo-lhe o convite que lhe foi dirigido desejou o mais franco sucesso a homenagem da Liga de Amadores de Football ao grande feriado nacional. [...]

Da renda do jogo de hoje será retirada uma porcentagem em benefício da Santa Casa de Misericórdia e outra para a Sociedade dos Homens de Côr, conforme anteriores deliberações da diretoria (Correio Paulistano, 13/05/1928, p. 6).

A matéria reforça as impressões do ano anterior, quando foi muito bem aceito pelo público assistente e pela sociedade local. Assim como em 1927, o jogo daquele ano reuniu novamente todas as honras de um evento festivo de cunho nacional. Para tanto, foi reforçado o convite às mesmas autoridades do primeiro "Preto x Branco".

Selecionado Branco contra Selecionado Preto

O importante jogo de hoje no campo da Floresta, em disputa da taça Princesa Isabel.

A entidade da rua João Briccola [LAF], desejando homenagear a grande data de 13 de maio, instituiu os jogos entre os alludidos combinados, obtendo a mais franca aceitação e ruidoso sucesso para sua feliz idea (FolHA DA MANHĀ, 13/05/1928, p. 10).

Em 1928, o time "preto" derrotou o "branco" pela segunda vez, vencendo-o por 4 a 2. Isso soou incompreensível ao jornal A Gazeta, já que a equipe branca contava com jogadores de renome: "dentre eles estavam quatro jogadores da equipe campeã do ano passado; nós não entendemos como um time tão forte foi derrotado" (A GAZETA, 14/05/28, p.6).

Uma das justificativas da vitória do time dos negros foi sugerida pelo jornal O Combate:

A grande partida de hontem

[...] desde os primeiros momentos, frente à perspectiva de um jogo titânico, a grande massa dos espectadores escolheu como seu favorito, que era o time Preto, e continuamente incentivou-o à frente num incontido desejo. Parecia que cada esforço da multidão era feito para ver os negros vencerem, e que ela via nessa vitória uma questão de honra [...] (O Combate, 14/05/28, p.6 citado por ANDREWs, 1998, p.334).

Aqui cabe pensar sobre a escolha do time dos pretos por parte dos torcedores, que teria sido um dos fatores determinantes para a vitória dos pretos. Essa escolha talvez indicasse o desejo de que os representados como mais fracos ou oprimidos vencessem, ou seja, um desejo de reparação, pelo menos ideológica. Ainda que naquele contexto o
Brasil estivesse sob uma ordem liberal, ambas as equipes eram vistas como diferentes por seu passado e "status". Isso fazia daquele um "jogo ritual”.

$\mathrm{O}$ ano de 1929 poderia ser decisivo. Caso o time dos brancos perdesse ou empatasse a partida, os pretos ficariam com a posse definitiva da taça, uma vez que completariam três vitórias consecutivas. No dia 13, a Folha da Manhã anunciou o jogo salientando o horário, o lugar, o significado da data e o fato de o jogo estar ganhando importância e se tornando uma prova tradicional.

Tradicional festival de 13 de Maio, da Liga de Amadores de Futebol - grande parida esportiva entre o combinado branco e o combinado de jogadores de côr.

À's 15 hs e meia de hoje no campo da A. A. Palmeiras, será realizado o importante jogo de futebol que há vários dias vem sendo noticiado, entre os selecionados branco e preto, da Liga de Amadores de Futebol. Esse jogo em disputa da Taça "Princesa Izabel" comemora a passagem de uma das mais importantes ephemeridades da história brasileira. Com ella, a LAF vem realizando annualmente, desde 1927, esse encontro e já conquistou os foros de prova tradicional. [...]

Este anno é o último da disputa. Si o selecionado preto vencer o encontro, ficará de posse do lindo trophéo. É de crer que o jogo da tarde de hoje desperte o mesmo interesse idêntico provocado nos anos anteriores (FolHA DA MANHÃ, 13/05/1929, p.4).

Como de praxe, os jogos repercutiram na imprensa nos dias posteriores que apresentou inclusive fotos relativas a ele.

$\mathrm{O}$ jogo de ontem entre os combinados Branco e Preto.

No "Ground" da floresta, foi proporcionado ontem a tarde a competição tradicional organizada pela liga de amadores de futebol para comemorar a data histórica de treze de maio.

Foi discutida uma interessante competição de futebol em que se empenharam as turmas Branca e Preta, para a posse da Princesa Izabel - doada pelo Sr. Dino Bueno quando presidente deste Estado. O torneio revestiu-se de grande brilhantismo atrelado ao campo do Palmeiras uma concorrencia bem avultada e entusiasmada os dois quadros atuaram regularmente, tendo o combinado Branco se ressentido, porém, de mais perfeita unidade entre seus elementos dianteiros. Os do quadro Preto souberam, por sua vez, se conduzir com bravura. Conseguindo esquentar 
a situação prática de luta. (CORREIo Paulistano, 14/05/1929, p.13).

O Correio reforça alguns acontecimentos recorrentes no evento e parece revelar que os brancos tiveram êxito no seu intento de evitar a vitória dos negros. Além disso, depreende-se a partir das matérias que, mesmo tendo sido trocado o governo do Estado, manteve-se a política de presentear com a taça a equipe que conquistasse três campeonatos seguidos ou quatro alternados.

O Estado de S. Paulo trouxe novos detalhes:

Os Brancos Empataram com os Pretos

O festival de hontem, no campo da Floresta

- empate de dois pontos, após um jogo falho de técnica.

Realizou-se hontem no campo do Palmeiras, na Floresta, o clássico festival do dia 13 de maio, promovido pela Liga de Amadores de Futebol em disputa da taça "Princesa Isabel".

Encontravam-se pela terceira vez, em três annos consecutivos, os selecionados de jogadores brancos e jogadores pretos dos clubes filiados a LAF, sendo que estes últimos tinham em seu favor victórias conquistadas nos dois primeiros annos. Quadros sem treinos, organizados quasi a última hora era evidente que não podiam proporcionar um bom jogo. Esperava-se, contudo, que o ardor e a rivalidade fossem razões suficientes para uma partida boa.

Tal não aconteceu, entretanto, o jogo desenvolvido pelos dois conjuntos foi falho, sob todos os pontos de vista, principalmente technico.

$\mathrm{O}$ quadro preto esforçou-se, e muito. Devia vencer mas não poude, apesar dos seus ataques serem muito mais perigosos e mais constantes. $[\ldots]$

Assim com ataques alternados cada bando procurando alcançar a victória termina o embate, com empate de dois pontos (O Estado de São Paulo, 14/05/1929, p.12).

Diferentemente dos anos anteriores, quando foi bastante elogiado, em 1929 o nível técnico da partida foi contestado, talvez em função da falta de treinos preparatórios para o jogo. Adiciona-se a isso a desorganização dos times, que fez com que a partida não fosse considerada de boa qualidade. Nem a rivalidade entre as equipes, que havia sido construída nos dois últimos anos, foi suficiente para tornar a disputa interessante.

A Folha da Manhã acrescentou maiores detalhes sobre a repercussão desse evento que ocupava lugar de destaque, a julgar pela sua divulgação em letras garrafais no alto da página, em que se lê:
Os selecionados branco e preto, da LAF, empataram após renhida lucta.

Bem poucas vezes este ano se viu o campo do Palmeiras tão cheio de affeiçoados ao esporte bretão. Em se tratando de partidas promovidas pela Liga dissidente pode-se mesmo taxar de extraordinário o número dos que queriam assistir alli hontem, ao annunciado jogo entre dois fortes selecionados da Liga: selecionado branco e selecionado preto. As duas turmas já são conhecidas em conjuncto, por ser esta a terceira vez que se defrontam, sempre na data de 13 de maio, commemorativa da abolição da escravatura no Brasil (FolHA DA MANHĀ, 14/05/1929, p.9).

Aqui temos um jornal da imprensa negra dizendo que o evento fazia parte das festividades daquele que era, aos seus olhos, um dos mais importantes acontecimentos da história brasileira. O Clarim, outro jornal da imprensa negra, noticiou que o evento daquele ano tinha um diferencial: era o primeiro jogo realizado após a incorporação da LAF pela APEA, ocorrida em 1929, como narra Mazzoni: 1929 encontrou as entidades e os clubes já cançados de uma luta inútil. Mas, faltava uma iniciativa decidida para se acabar com a cisão que vinha existindo desde 1926. No entanto, o acordo não seria fácil, como realmente não foi. A luta terminou quando alguns clubes da LAF forçaram a sua adesão à APEA e esta concordou. Daí precipitou-se a pacificação tão desejada, desparecendo em seguida a LAF. Todavia, o Paulistano, fiel aos seus princípios, deixou o futebol extinguindo também a entidade que havia fundado. Todos os demais clubes foram readmitidos pela APEA (MAZZONI, 1950, p.219).

Seria, portanto, o primeiro "Preto x Branco" realizado sob a responsabilidade da APEA em conjunto com o C. A. Brasil e aquele jornal, sendo que esses dois últimos eram instituições destinadas aos negros. a tarde esportiva de 13 de maio, este anno, será patrocinada pelo C. A. Brasil, com a coadjuvação do "Clarim d'Alvorada".

Grafar os esforços do Clube Athletico Brasil, apoiado pelo órgão da mocidade negra [aqui uma autorreferência do Clarim da Alvorada] e outros representantes de nomes evidenciados de nossa classe, a Associação Paulista de Esportes Athleticos, concedeu e officializou a data de 13 de maio, para a realização do grande festival esportivo que fora transferido por motivo de força maior. Essa tarde esportiva vai ser uma das partidas mais interessantes jogadas nestes últimos tempos 
em nossa capital. A razão desta afirmativa está baseada na pacificação reinante nos nossos meios esportivos - não temos mais dualidade - este é o primeiro encontro entre Preto $\mathrm{x}$ Branco sob o patrocínio da A.P.E.A.

Grande será a assistência que afluirá na tarde de 13 de maio, para assistir, pela primeira vez, o mais sério encontro entre os nossos elementos unidos, quer de um lado como de outro. (O CLARIM DA Alvorada, 13/04/1930, p.4)

Realizado pelo quarto ano consecutivo, o jogo ganhava status de prova tradicional. Tal prestígio fez com que ele continuasse sendo promovido, apesar da transição política que anunciava novos rumos para o futebol paulista. O que significou a incorporação da LAF pela APEA? A derrota do amadorismo ou a vitória do profissionalismo? Os jornais não dão respostas, mas o fato de a APEA manter, em parceria com clubes e jornais que representavam os pretos da capital paulistana, um evento idealizado pela liga incorporada sugere as funções ambivalentes que aqueles jogos vinham assumindo: positivar a imagem da nação brasileira no que diz respeito às questôes raciais e continuar dando visibilidade aos pretos para que pudessem ser absorvidos pelo mercado do futebol profissional que estava em desenvolvimento naquele período.

COMBINADOS PRETO-BRANCO LUCTARÃO EM TREZE DE MAIO.

O C.A. Brasil prepara o programma futebolistico com que brindará o nosso mundo esportivo em 13 de maio.

É uma jornada que promette brilhantismo e será, por certo, a continuação dessa cordialidade entre pretos e brancos no futebol paulista. Muitas e valiosas glórias nos têm dado esses valentes rapazes, desde 1919, quando, quebrando velhos e carunchosos preconceitos de côr, o dr. Ramos Caiado, então presidente da A. A. Mackenzie, introduziu em sua turma um grupo de rapazes negros.

Era a porta aberta para as grandes posições que hoje occupam, para gloria de nossa gente.

Pois essa praxe posta em pratica pela extinta LAF de se homenagear a data com uma partida annual entre pretos e brancos, ao contrário do que se esperava, não desapareceu com a morte da liga de amadores.

O C. A. Brasil, representativo de homens negros, tendo cessão de data, está organisando uma partida para o proximo dia 13 de Maio.

O programa tem merecido especial cuidado por parte dos dirigentes do Brasil para que nada falte e seja igual em brilho às jornadas anteriores.
Todas as vezes que se encontraram os conjunctos Brancos e Preto têm proporcionado à assistência uma lucta renhida e cheia de emoçóes.

Dando-se o facto de hoje, estar unificado o nosso futebol, mais renhida será essa lucta, pois, o conjucto branco será mais aguerrido e porá à prova os homens de cor que nessas partidas annuaes têm vencido os seus adversários.

TAÇA DR. JULIO PRESTES

O sr. Presidente do Estado offereceu uma linda e rica taça, que recebeu o nome de sua excia., para ser disputada na prova principal do dia.

A dadiva do dr. Julio Prestes veiu evidenciar a estima em que são tidos os homêns de cor, contribuindo assim, grandemente, para o brilho do festival do Brasil. (FolHa DA Manhâ, 09/05/1930, p.9).

A matéria revela que a cordialidade era um valor marcante e presente entre brancos e pretos no futebol paulista. Tanto o próprio jogo quanto a forma como ele era vivenciado eram isentos de manifestações de violência física. No entanto, não deixa de denunciar o preconceito de cor presente nos primórdios do esporte em São Paulo em um dos clubes elitistas daquela capital: o Mackenzie. A superação do preconceito teria sido responsável não só pela participação do preto no esporte, como também em outros espaços da sociedade brasileira dos quais estiveram alijados.

\section{O FESTIVAL DO DIA TREZE DE MAIO}

A expectativa em torno do encontro dos brancos contra pretos - os premios instituídos.

Depois de amanhã, finalmente, teremos, no gramado tradicional A Floresta, o encontro annual dos combinados Preto e Branco.

É elle o assumpto geral das nossas rodas esportivas, e os comentarios variam constantemente, não raro se inflammando os torcedores.

O nosso publico que sempre deu demonstrações frizantes de sympathias pelos homens de cor, aplaudindo-os e entusiasmando-os, ainda desta vez, pelo que se observa entre os nossos afficionados, não mudará de favoritos.

Enfrentando conjuncto muito mais forte que os antagonistas anteriores, como se portarão os rapazes do quadro preto?

É o que veremos no dia 13.

Os preparativos vêm sendo animados para a lucta que se annuncia formidável.

\section{CONVITES AS ALTAS AUTORIDADES}

Foram convidadas as altas autoridades municipaes, estadoaes e federaes para presenciar a lucta, devendo estar presente o sr. presidente do Estado (FolHa DA Manhã, 11/05/1930, p.14). 
Como nos anos anteriores, o time dos pretos continuou sendo o favorito e as mesmas autoridades políticas foram convidadas para o jogo. Todavia, não temos a confirmação se tais autoridades retribuíram a gentileza, prestigiando pessoalmente aquela festividade que ganhava status de prova tradicional. O Estado de S. Paulo limitou-se a anunciá-la, adjetivando-a de interessante.

Brancos vs. Pretos

A exemplo do que tem sido feito em annos anteriores depois de amanham, dia 13 de maio, será realizada nessa capital uma interessante competição futebolística entre dois quadros constituídos de jogadores brancos e de côr, e que vão ao campo com a designação de quadros "branco" e "preto" [...] (O Estado de S. Paulo, 11/05/1930, p.10).

No dia seguinte, o mesmo jornal reforça esse adjetivo e adiciona o fato de que, diferentemente dos anos anteriores, as equipes estavam sendo organizadas com capricho e acerto.

A Laf faz realisar amanhan o clássico festival do dia 13 de Maio.

$\mathrm{O}$ jogo de amanhan promete ser muito interessante, pois os dois quadros estão organizados com capricho e acerto (O Estado de S. Paulo, 12/05/1930, p.15).

No dia do jogo, o Correio Paulistano se ocupou de anunciar o evento. Hoje suas páginas nos proporcionam uma leitura das expectativas que o jogo despertava junto à população.

A partida annual de 13 de Maio

O enthusiasmo pela lucta - várias notas

Hoje, finalmente, teremos no gramado tradicional da Floresta o encontro annual dos combinados Preto e Branco.

É esse o assumpto geral das nossas rodas sportivas, e os comentários variam constantemente não raro inflamando os torcedores.

Nosso público que sempre deu demonstração frizante de sympathias pelos homens de cor, applaudindo-os e enthusiasmando-os, ainda dessa vez, pelo que se observa entre os nossos aficcionados, não mudará de favoritos.

Enfrentando conjunto muito mais forte que os antagonistas anteriores, como se portarão os rapazes do quadro de Petro.

Os preparativos foram de molde a inferior animação para a lucta que se annuncia.

CONVITES A'S ALTAS AUTORIDADES

Foram convidadas as altas autoridades municipaes, estaduaes e federaes para presenciar o evento. (Correio Paulistano, 13/05/1930, p.10).
Já o Estado de S. Paulo se limitou a informar o estádio em que seria realizada a partida, que haveria jogos preliminares e que o jogo deveria receber um bom público:

O festival de hoje no campo do S. Paulo F. C.

Os quadros "Brancos" e "Pretos" vão disputar uma taça - haverá 2 partidas preliminares.

Realiza-se hoje no campo do S. Paulo F. C. á tarde um festival esportivo que deve levar à Floresta vultuosa assistência. (O Estado de S. Paulo, 13/05/1930, p.9).

No dia seguinte ao jogo, as páginas dos jornais paulistas anunciaram a terceira vitória dos negros em quatro jogos disputados.

Secção Sportiva

O Festival de Hontem, Commemorativo à Data

$\mathrm{O}$ selecionado preto venceu a prova

Organizado pelo C. A. Brasil logrou despertar grande interesse o encontro tradicional entre brancos e pretos, e cuja realização hontem verificada no campo do S. Paulo F. C. obteve grande brilho. O campo da Chácara da Floresta ficou literalmente repleto, tal o interesse que a partida despertava. [...] (Correio Paulistano, 14/05/1930, p.8).

$\mathrm{O}$ jogo seguia repercutindo em outros jornais paulistanos, mas parece que houve um equívoco de alguns jornais em relação ao resultado da partida. Enquanto o Estado deu o placar de 5 a 0, no jornal Folha da Manhã lia-se:

Os "pretos" venceram os "brancos"

O encontro de hontem na Floresta

A contagem foi de 4 a 0

Esteve bem interessante a tarde esportiva de hontem no campo do São Paulo, no Floresta. O encontro principal, entre os seleccionados branco e preto, corresponde á espectativa.

Os brancos, apesar de não apresentarem o seu quadro completo, conseguiram oppor resistência aos seus adversários que jogaram optimamente. $\mathrm{O}$ escoro de quatro a zero não espelha bem o que foi a interessante partida. Por que durante $o$ tempo todo não houve domínio. Os dois bancos se esforçaram porque souberam aproveitar as oportunidades que se lhes depararam. A victoria no entanto foi merecida. A contagem pela lógica é que devia ser outra. (FolHA DA ManHĀ, 14/05/1930, p.9).

Não foi apenas a imprensa convencional que se ocupou do evento. A partir daquele ano a "imprensa negra", através do jornal O Progresso, apresentou uma matéria que diz que o "Preto x Branco" foi idealizado para "comemorar uma das datas 
mais caras ao coração brasileiro." (O Progresso, 20/04/1930, p.4).

Acreditando em ANDREWs (1998), que disse que os jogos haviam terminado em 1930, pensei em dar por encerrada a pesquisa nos microfilmes da Biblioteca Nacional. Entretanto, o rigor acadêmico me fez desconfiar do historiador brasilianista e checar o ano de 1931. Foi quando, para minha surpresa, vi matérias anunciando que o jogo seria realizado novamente naquele ano.

Amanhan a noite, no campo do S. Paulo F. C. realisa-se o tradicional encontro entre os selecionados Branco e Preto, promovido pelo C. A. Brasil. Como se tem verificado anteriormente, é grande o entusiasmo do público admirador, sendo de se esperar uma assistência das maiores.Á senhorita Iolanda Pereira, presentemente entre nós, foi feito um convite para assistir e dar início ao jogo. Possivelmente o festival nocturno de amanhan, no campo do S. Paulo, contará com a presença da mais bella de 1930 [...] (O Estado de S. Paulo, 12/05/1931, p.6).

Os eventos anteriores receberam a presença de autoridades políticas, militares e esportistas, e o de 1931 não fugiu a essa regra, sendo prestigiado por celebridades nacionais. Naquela ocasião, o "Preto x Branco" receberia a visita de Yolanda Pereira, "a mais bella", que, em agosto de 1930, havia sido a primeira brasileira a conquistar o título de Miss Universo.

No dia do jogo, o mesmo jornal anunciou FESTIVAL ESPORTIVO DESTA NOITE, NO CAMPO DO S. PAULO

hoje a noite, o Club Athlético Brasil realiza uma festa esportiva contendo o principal atrativo, o tradicional encontro de branco e preto que vem sendo realizado há seis anos alcansando sempre grande sucesso. $\mathrm{O}$ enthusiasmo e interesse que vem sendo aguardado neste jogo são plenamente justificáveis, pois tanto os jogadores brancos quanto os pretos estão, ao que geralmente se affirma, optimamente preparados (O Estado de S. Paulo, 13/05/1931, p.6).

Essa matéria reforça o fato de que aquele era um evento festivo e atualiza a tradição sobre aquele jogo, que já estava em sua $5^{a}$ edição. Ademais, reforça o fato de que o evento sempre obtinha sucesso e que as equipes estavam bem preparadas tecnicamente, como também foi destacado pela Folha da Manhã:

Realiza-se hoje o tradicional encontro entre os seleccionados dos pretos e brancos. A grande data da libertação dos escravos de há muito vem sendo commemorada, pelos futebolistas paulistanos, com a realização de tão grande encontro, tanto o quadro dos pretos, como o dos brancos, apresentar-se-ão integrados pelos nossos mais perfeitos futebolistas. (FOLHA DA MANHÃ, 13/05/1931, p.11).

Aquele jogo que estava sendo anunciado podia ser o último dos "Preto x Branco". Se os pretos vencessem, completariam a quarta vitória alternada e ficariam com a posse definitiva da taça "Princesa Izabel”. Para evitar esse desfecho o time dos brancos deveria evitar a vitória do adversário. E conseguiu. No dia 14, como de costume, o Estado limitou-se a anunciar o placar: "Notícias do Esporte - Última Hora: Brancos (5) vs. Pretos (2)" (O Estado de S. Paulo, 14/05/1931, p.2).

A Folha da Manhã, por sua vez, trouxe maiores detalhes sobre a primeira vitória do time dos brancos.

Futebolistas pretos foram derrotados pelos brancos, no jogo de hontem por 5 a 2.

O jogo realizado á noite no gramado do $S$. Paulo F. C., agradou bastante a enorme assistência que ali accorreu.

Numerosa foi a assistência que affluiu ás dependências do campo da Floresta afim de assistir o desenvolver do tradicional encontro entre o selecionado dos pretos e dos brancos. (FOLHA DA ManHĀ, 14/05/1931, p.8).

Na página 12 do mesmo jornal, a matéria descreveu os gols e finalizou: "mais algumas jogadas sem importância e termina as 23,55 hs o prélio, com a contagem de cinco tentos contra dois, a favor do selecionado dos brancos" (FolHa DA MANHÃ, $14 / 05 / 1931$, p.12). Novamente os jornais nos apontam que o jogo agradou aos espectadores, que, ao que parece, compareceram em bom número ao estádio. Além disso, revelam que quando o dia " 13 de maio" ocorria em um dia útil, o jogo acontecia no turno da noite, mas não deixava de ser realizado.

A pesquisa sobre o ano de 1931 foi encerrada e foi realizado o mesmo procedimento para o ano de 1932 para ver se encontrava alguma menção ao jogo. Não foi encontrando, e tampouco alguma explicação para a interrupção dos jogos. Achei então que a pesquisa junto aos microfilmes havia terminado. Posteriormente, lendo o livro de STORTI e Fontenelle (1997), A história do campeonato paulista, descobri que houve edições desses jogos em 1938 e 1939.

Por esse motivo retornei à Biblioteca Nacional para repetir os mesmos procedimentos que fiz em relação aos jornais do final da década de 20 e início da de 30. Retornei às fontes a fim de encontrar 
alguma menção aos jogos nos anos de 1938 e 1939, mas foi em vão. Lendo os jornais pude observar que a sociedade paulistana anunciou várias festividades para comemorar o cinquentenário da abolição, mas os jogos não foram mencionados. O único anúncio de competição esportiva destinada às "raças" naquele período foi feito pelo Correio Paulistano em 1939, sobre a disputa de uma prova de atletismo destinada exclusivamente a negros e mestiços, como se lê: A VI disputa da prova atlética "13 de Maio". Commemorando a passagem do aniversário da Lei Áurea o clube negro de cultura social promoverá a tradicional "prova 13 de Maio", no qual somente participarão corredores negros e mestiços (Correio Paulistano, 13/05/1939, p.9).
Onde encontrar esses jogos? STORTI e FONTENELLE (1997) disseram que em 1938 o jogo terminou em 1 a 0 para os pretos. Pelas contas, esse seria o último jogo, já que ele trataria a quarta vitória alternada dos pretos, o que daria por encerrada a disputa. Todavia, curiosamente, os autores indicaram que em 1939 houve a realização de uma outra partida, vencida pelos brancos por 2 a 0 . Por que essa última partida foi realizada, uma vez que a competição, a julgar pelo seu regulamento, deveria ter sido encerrada em 1938?

Fiquei com essa dúvida até o final de julho de 2010, quando, em uma visita ao Museu da Federação Paulista de Futebol (FPF), pode-se ver a taça abaixo, da edição de 38 .

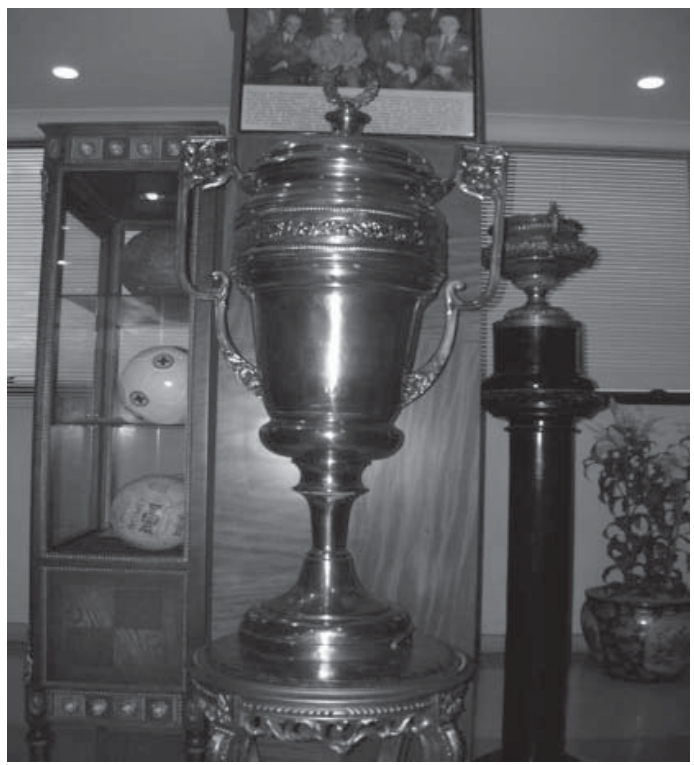

FIGURA 1 - Museu da Federação Paulista de futebol (jul./ 2010).

Sobre esse móvel há dois papéis, com a logo da FPF e as informações necessárias para decifrarmos esse enigma. Nesses papéis, lê-se:

\section{TAÇA AO VENCEDOR}

O calendário do futebol paulista na década de 30 marcava a disputa de um jogo beneficente, cuja arrecadação era destinada a casas de caridade, com Sanatorinhos, Santa Casa da Misericórida, entre outras. Esse jogo era disputado geralmente no dia 13 de maio, data da bolição (sic) dos escravos, que era um dos feriados nacionais. Ele tornou-se famoso sob a denominação de 'Branco e Preto'. Formaram-se dois selecionados, um dos jogadores negros e outro de brancos. Esta taça foi disputada no dia 12 de maio de 1938 , a imprensa não divulgou o resultado deste 'Branco e Preto', muito provavelmente por ter sido ano da disputa do III Campeonato Mundial de Futebol, assunto que polarizou o noticiário.

$\mathrm{N}^{\circ}$ do tombo: 25

Descobrimos os motivos pelos quais o jogo não foi divulgado em 1938: recebia a concorrência da Copa do Mundo, que seria realizada de 4 a 19 de junho daquele ano. Faltando pouco menos de um mês para sua realização, a Copa de 1938, como acontece até hoje, concentrou toda a atenção esportiva.

Outra hipótese sobre a falta de divulgação do jogo de 1938 foi apresentada por uma segunda folha, embaixo da mesma taça, na qual se lê:

A Gazeta Esportiva, que não deixa de registrar a disputa do 'Branco e Preto', curiosamente não fez nenhuma referência ao tradicional jogo beneficente de 1938, o que nos leva a supor que neste ano ele não foi disputado na capital. 
Em seu lugar, o jornal noticiou o 'Branco e Preto' realizado no dia 13 de maio, na cidade de Bragança Paulista com renda, como sempre, destinada a casas de caridade local. Segundo o jornal, o jogo foi patrocinado pela Comissão de Festejos do 13 de maio, entidade que ainda cedeu a bola e foi abrilhantado pela corporação musical ' 15 de outubro'.

As equipes, compostas por jogadores do Esperança F.C., agremiação que vinha se destacando na cidade, foram estas:

Brancos: Caetano, Tufani e Durval; Orlando, Canhoto e Gozzaneo; Juca, Alonso, Gomes, Quico e Zanilla.

Pretos: Ramos, Salvador e Zinho; Trajano I, Dirceu e Jorge; Trajano II, Euclydes, Turíbio, Aparecido e Rufino.

O jogo terminou com vitória dos Brancos $2 \times 0$ e a reportagem não cita quem marcou os gols.

Essa hipótese parece ser mais plausível. Enquanto era realizada a pesquisa nos jornais paulistanos de 1938 e 1939, observamos que não havia apenas matérias exclusivas sobre a Copa. Se havia outras notícias sobre futebol, e até mesmo outros esportes, por que não falar do "Preto x Branco"? Ao contrário do que foi dito pelos autores, não foram os pretos os vencedores de 1938, e sim os brancos. Tanto é verdade que isso forçou a realização de uma sétima partida, realizada em 1939, essa, sim, vencida pelos pretos. O placar final das sete edições do Preto e Branco foi: 4 vitórias dos pretos, 2 dos brancos e 1 empate.

Além da capital paulistana há indícios de jogos dessa mesma natureza ritual em outras cidades do Estado de São Paulo cujo principal atrativo é um evento esportivo que polariza brancos e negros. Em linguagem antropológica, diria Roberto DAMATTA (1990), o exotismo que garante a atratividade do evento é a dramatização das representações socialmente construídas sobre as raças através dos diferentes esportes.

Um ponto de convergência entre esses jogos é que eles surgiram e foram disputados com a finalidade de celebrar o fim da escravidão. A escolha da data não foi fortuita, uma vez que nossas lembranças se fortificam graças às narrativas que são reforçadas por meio de comemoraçōes públicas de acontecimentos que marcaram a história coletiva (Rodrigues Da SiLVA, 2002). A memória coletiva se constrói no processo de "rememoração" social, cuja função é justamente impedir o esquecimento.

Com efeito, a realização de uma partida dessa natureza no dia comemorativo da abolição da escravatura teria a função de prevenir do esquecimento e manter viva a lembrança da escravidão na história do Brasil, além de corroborar a construção de um país próspero e que seria um pólo de resistência ao pessimismo das ideologias racistas do século XIX.

Poderíamos questionar, se é que não existia conflito ou tensão: por que os jogos não eram realizados com brancos e pretos atuando em uma mesma equipe? A resposta pode estar no fato de que um jogo com essas características não teria nada de especial. O diferencial desses jogos era colocar pretos e brancos, socialmente desiguais, em lados opostos, para jogarem em igualdade de condições.

A positivação da mestiçagem ${ }^{3}$ através do futebol reforçava o discurso distintivo de uma nação que, perante as demais, sobretudo aquelas com passado escravocrata, teria encontrado um caminho para que os antagonismos culturais/raciais fossem equilibrados ou amainados. A idealização e realização dos jogos ocorreram naquele contexto em que o Brasil, no que diz respeito ao quesito étnico-racial, era tomado como um modelo a ser seguido, reforçando a imagem paradisíaca das interações raciais.

\section{Notas}

1. Schwarcz (2001) utilizou o mesmo tratamento metodológico quando, na ocasião de seu livro Retrato em branco e preto, pesquisou o imaginário paulistano nos jornais do fim do século XIX.

2. [O presidente anterior, Carlos de Campos, faleceu em 27/04/1927, antes de terminar seu mandato. O prazo restante foi cumprido pelo Presidente do Senado Estadual, Antônio Dino da Costa Bueno, que assumiu o posto como $13^{\circ}$ presidente. Dino Bueno, como era conhecido, ficou no cargo de forma interina de abril a julho de 1927, quando foi substituído por Júlio Prestes de Albuquerque, $14^{\circ}$ presidente, que governou até maio de 1930. A designação "presidente do estado" era o que hoje entendemos como governador do Estado.] Fonte: Portal do Governo do Estado de São Paulo (<www.saopaulo.sp.gov.br>), disponível em: $<$ http://www.galeriadosgovernadores.sp.gov.br/03galeria/galeria.htm\#12>, última consulta em: 16/10/2010.

3. A positivação dessa imagem fez com que a UNESCO , a partir do Programa de Pesquisas sobre Relações Raciais no Brasil, financiasse pesquisas no país, como se desejasse entender os segredos da democracia racial e o sucesso das 
relações raciais no Brasil para ensiná-los às outras nações. Segundo Marcos MAIO (1998), essa imagem "foi o principal pré-requisito para transformar o País em objeto de interesse e de pesquisa da UNESCO” (p.17). A escolha do Brasil não foi fortuita: "o Brasil foi escolhido, em perspectiva comparada com a negativa experiência racial norte-americana, para ser um dos pólos de problematização, verificação e superação dos grandes dilemas vividos pela humanidade em matéria étnica” (MAIO, 1998).

\begin{abstract}
The soccer in the construction of the national identity: an analysis concerning the "black $\mathrm{x}$ white" games

This paper aims to understand the meanings of a soccer match, between players who self-declared themselves as black or white, occurred in São Paulo on May 13th, the date commemorating the end of slavery: the game "Black $x$ White". For this, we focused on journalistic material published by leading newspapers of São Paulo from May 10th to 15th, during 1927 and 1939, when the games were held. Additionally, a visit to the museum of the Paulista Football Federation provided the information necessary to understand the trajectory of these games. We concluded that the idealization of a game like this on "May 13th" would have the purpose not only to prevent forgetfulness and to keep alive the memory of slavery, but also to strengthen the image of a country taken as a model to be followed, with respect to the ethnic-racial subject.
\end{abstract}

UNITERMS: Soccer; National identity; Game "Black X White".

\title{
Referências
}

A COMMEMORAÇÃO da Lei Áurea: combinado branco vs combinado preto. O Estado de S. Paulo, São Paulo, 13 maio 1927. p.6.

A LAF faz realisar amanhan o clássico festival do dia 13 de Maio. O Estado de S. Paulo, São Paulo, 12 maio 1930. p.15. ANDREWS, G.R. Negros e brancos em São Paulo (1888-1988). Bauru: EDUSC, 1998.

A PARTIDA annual de 13 de Maio: o enthusiasmo pela lucta - várias notas. Correio Paulistano, São Paulo, 13 maio 1930. p.10.

A VI disputa da prova atlética “13 de Maio”. Correio Paulistano, São Paulo, 13 maio 1939. p.9.

BRANCOS vs. Pretos. O Estado de S. Paulo, São Paulo, 11 maio 1930. p.10.

COMBINADOS Preto-Branco luctarão em Treze de Maio. Folha da Manhã, São Paulo, 09 maio 1930. p.9.

DaMATTA, R. Carnavais, malandros e heróis: para uma sociologia do dilema brasileiro. 5. ed. Rio de Janeiro: Guanabara, 1990. EM DISPUTA da taça Princesa Izabel. Correio Paulistano, São Paulo, 13 maio 1928. p.6.

FESTIVAL esportivo desta noite, no campo do S. Paulo. O Estado de S. Paulo, São Paulo, 13 maio 1931. p.6. FOLHA DA MANHÂ, 13 maio 1931, p.11.

FUTEBOL - a commemoração da Lei Áurea: combinado branco vs combinado preto. A brilhante victória dos negros por 3 a 2. O Estado de S. Paulo, São Paulo, 14 maio 1927. p.6.

FUTEBOLISTAS pretos foram derrotados pelos brancos, no jogo de hontem por 5 a 2. Folha da Manhã, São Paulo, 14 maio 1931. p.8.

GEERTZ. C. A interpretação das culturas. Rio de Janeiro: Zahar, 1973.

LAF: Comunicado oficial - Selecionado Branco vs Selecionado Preto. Correio Paulistano, São Paulo, 09 maio 1927. Sport, p.6.

LIGA de Amadores de Football: a competição de hontem em homenagem a data de 13 de maio - victória do combinado negro - outras notas. Correio Paulistano, São Paulo. 14 maio 1927. p.6.

MAIO, M.C. Apresentação. In: PINTO, L.A. O negro no Rio de Janeiro: relações de raça numa sociedade em mudança. 2. ed. Rio de Janeiro: UFRJ, 1998. 
MAZZONI, T. História do futebol brasileiro. São Paulo: Olimpicus, 1950.

O CLARIM DA ALVORADA, São Paulo, 13 abr.1930. p.4.

O FESTIVAL de hoje no campo do S. Paulo F. C. O Estado de S. Paulo, São Paulo, 13 maio 1930. p.9.

O FESTIVAL de hontem, commemorativo à data. Correio Paulistano, São Paulo, 14 maio 1930. p.8.

O FESTIVAL de hontem da LAF: o selecionado preto venceu o branco. Folha da Manhã, São Paulo, 14 maio 1927. p.8.

O FESTIVAL do dia Treze de Maio: a expectativa em torno do encontro dos brancos contra pretos - os premios instituídos.

Folha da Manhã, São Paulo, 11 maio 1930. p.14.

O ESTADO DE S. PAULO, São Paulo, 12 maio 1931. p.6.

O JOGO de ontem entre os combinados Branco e Preto. Correio Paulistano, São Paulo, 14 maio 1929. p.13.

O GRANDE festival de hoje no campo do Palmeiras: combinado Preto VS. combinado Branco da LAF - outras notas.

Correio Paulistano, São Paulo, 13 maio 1927. Sport, p.5.

OS BRANCOS empataram com os Pretos. O Estado de São Paulo, São Paulo, 14 maio 1929. p.12.

OS "PRETOS” venceram os "brancos". Folha da Manhã, São Paulo, 14 maio 1930. p.9.

OS SELECIONADOS branco e preto, da LAF, empataram após renhida lucta. Folha da Manhã, São Paulo, 14 maio 1929. p.9.

PIRES, A.L.C.S. "Associações de homens de cor": imprensa negra, movimentos negros e ideologias sociais (1915-1937). In: SALGUEIRO, M.A.A. (Org.). A república e a questão do negro no Brasil. Rio de Janeiro: Museu da República, 2005. RODRIGUES FILHO, M. O negro no futebol brasileiro. 4. ed. Rio de Janeiro: Mauad, 2003.

SCHWARCZ, L.M. Retrato em branco e preto: jornais, escravos e cidadãos em São Paulo no final do século XIX. São Paulo: Companhia das Letras, 2001.

SELECIONADO Branco contra Selecionado Preto. Folha da Manhã, São Paulo, 13 maio 1928. p.10.

SILVA, H.R. "Rememoração"/comemoração: as utilizações sociais da memória. Revista Brasileira de História, São Paulo, p.425-38, 2002.

STORTI, V.; FONTENELlE, A. A história do Campeonato Paulista: 1902-1996. São Paulo: PUBLIFOLHA, 1997. TRADICIONAL festival de 13 de Maio, da Liga de Amadores de Futebol: grande parida esportiva entre o combinado branco e o combinado de jogadores de côr. Folha da Manhã, São Paulo, 13 maio 1929. p.4.

ENDEREÇO

Antonio J orge Gonçalves Soares

R. Alzira Cortes, 5 - apto. 106 - Botafogo 22260-050 - Rio de J aneiro - RJ - BRASIL e-mail: ajgsoares@gmail.com
Recebido para publicação: 31/ 08/ 2011

Aceito: 03/11/2011 